\title{
Associations of homelessness and residential mobility with length of stay after acute psychiatric admission
}

\author{
Alex D Tulloch ${ }^{1 *}$, Mizanur R Khondoker ${ }^{1,2}$, Paul Fearon $^{1,3}$ and Anthony S David ${ }^{1}$
}

\begin{abstract}
Background: A small number of patient-level variables have replicated associations with the length of stay (LOS) of psychiatric inpatients. Although need for housing has often been identified as a cause of delayed discharge, there has been little research into the associations between LOS and homelessness and residential mobility (moving to a new home), or the magnitude of these associations compared to other exposures.

Methods: Cross-sectional study of 4885 acute psychiatric admissions to a mental health NHS Trust serving four South London boroughs. Data were taken from a comprehensive repository of anonymised electronic patient records. Analysis was performed using log-linear regression.

Results: Residential mobility was associated with a 99\% increase in LOS and homelessness with a 45\% increase. Schizophrenia, other psychosis, the longest recent admission, residential mobility, and some items on the Health of the Nation Outcome Scales (HoNOS), especially ADL impairment, were also associated with increased LOS. Informal admission, drug and alcohol or other non-psychotic diagnosis and a high HoNOS self-harm score reduced LOS. Including residential mobility in the regression model produced the same increase in the variance explained as including diagnosis; only legal status was a stronger predictor.

Conclusions: Homelessness and, especially, residential mobility account for a significant part of variation in LOS despite affecting a minority of psychiatric inpatients; for these people, the effect on LOS is marked. Appropriate policy responses may include attempts to avert the loss of housing in association with admission, efforts to increase housing supply and the speed at which it is made available, and reforms of payment systems to encourage this.
\end{abstract}

Keywords: Length of stay, Hospitals psychiatric, Mental disorders, Residential mobility, Homeless persons

\section{Background}

The length of stay (LOS) of psychiatric inpatients continues to be highly variable, despite a trend towards overall reduction in most developed countries [1]. For example, an analysis of English psychiatric hospital admissions in 1999-2000 demonstrated that median LOS was 15 days, but $9 \%$ of admissions lasted 90 days or more, and 1\% lasted a year or more [2]. Numerous studies have attempted to explain this variation, which arises both at individual patient level and also at provider level

\footnotetext{
* Correspondence: alex.tulloch@kcl.ac.uk

'King's College London, King's Health Partners, Institute of Psychiatry, De Crespigny Park, London SE5 8AF, UK

Full list of author information is available at the end of the article
}

[3]. Our systematic review of the many studies on LOS in US mental health services [4] indicated that psychosis and female gender are associated with increased LOS, while discharge against medical advice, prospective payment, being married, being detained and either younger or middle age are associated with decreased LOS. However, the proportion of variance in LOS explained in these studies was rarely greater than 20-30\%. Although the mechanisms by which these factors influence LOS tend not to be discussed in detail, our presumption is that any associations need to be explained with reference to the behaviour of health care professionals.

A group of factors that have been little explored in studies of LOS are variables related to housing and 
homelessness. The importance of such factors is twofold: they may serve to explain additional variation in LOS, and, more importantly, they are factors which at least in principle could be addressed by practical measures to increase the availability of housing and the speed with which it is made available. During the preparation of our systematic review [4], we found only two studies which examined such factors among the 106 that we screened in full for inclusion (see below); similarly, housing-related factors were neither examined in previous high-quality studies of LOS in England [5,6], Germany [7] and Scandinavia [8], nor in case-control studies of long-stay versus typical length admissions performed in the US [9] and in Switzerland [10,11]. Studies of LOS which have looked at housing-related factors include a large Swiss analysis [12], which found that living conditions (including homelessness) was one of several variables strongly associated with LOS; an Australian study of LOS based on measures including the Health of the Nation Outcome Scales (HoNOS; [13]), which found a strong positive association with the HoNOS problems with living conditions item [14]; a large study of LOS in New York [15], which found a strong positive association with homelessness; a Californian study of a Veterans' Administration Health Center with access for a "hoptel" for homeless patients enabling early discharge, which found, in contrast to the New York findings, and presumably due to the study intervention, that LOS for homeless patients did not differ from those who were housed [16]; and our own small case-control study of "long-stay" patients in psychiatric services serving four South London boroughs which found that long-stay was associated with need for rehousing [17].

The relative infrequency with which these variables have been examined in studies of LOS contrasts with their prominence in the UK literature on "delayed discharge" [18,19]. Hospital admissions categorised as delayed discharges (or delayed transfers of care) are those which are judged to have been prolonged beyond that which would have been necessary in the absence of the factor responsible for the delay. Studies of delayed discharge have been performed both in samples of longstay patients and in prevalent samples of psychiatric inpatients. A study of 15 mental hospitals in England and Wales during 1972 and 1973 found that one third of those in hospital for between 1 and 3 years could have been discharged had suitable accommodation been available [20]. A similar UK-wide study performed in 1992, after 20 years in which the number of psychiatric beds nationally had halved, found that $61 \%$ of those who had been in hospital for between 6 months and 1 year were considered by the treating clinician to be more appropriately cared for outside hospital [21]. A further study of two small cohorts of long-stay patients found that $60 \%$ did not need to be in hospital and would have been discharged had suitable accommodation been available [22]. Among various prevalent samples of psychiatric inpatients, the proportion classified as being a delayed discharge either due to lack of housing or to which lack of suitable housing contributed was 356/227 (15\%) [23], $396 / 3710$ (11\%) [24] in two London-based studies; and $289 / 2236(13 \%)$ [25] in a national survey.

An advantage of attempting to examine variation in LOS through the prism of delayed discharge is that this concept focuses on the effect of the cause of the delay on clinical decision-making and the practical consequences of ameliorating the cause of the delay, and therefore explicitly relates longer hospital stay to decisions made by staff in relation to some defined problem, be that housing-related or due to delay in arranging a suitable package of care, etc. However, defining a delayed discharge depends on a subjective judgment of what would have happened to a patient in the absence of the putative delaying factor, and, furthermore, this method cannot be symmetrically applied to other factors which may influence LOS - it is likely to be meaningless or impractical to imagine, for example, what a patient's LOS might have been had they had a different mental illness or other individual characteristic. Therefore, we consider that it is preferable to study LOS itself, and to examine the association between LOS and the factors thought to be responsible for delayed discharge alongside other factors. In the case of delay due to housing-related issues, we suggest that healthcare professionals tend to delay the discharge of patients who are homeless-because such patients either need rehousing or at least need to be better stabilised before returning to tenuously held accommodation-and that they also tend to delay the discharge of patients who are anticipated to move residence (if the new residence is assumed to be more suitable on health grounds). It follows that we should seek to estimate the associations between LOS and homelessness and between LOS and residential mobility-the latter is defined here as moving from one address to another or, if previously homeless, moving into a new address, and is understood as being associated with LOS because of the anticipatory effects referred to above.

Homelessness is well-described among psychiatric inpatients [26-35], while hospital admission is the most consistently replicated association with residential mobility among those with mental illness [36-42]. That homelessness and residential mobility have been so little examined in the literature on LOS probably reflects their being infrequently included in sets of routinely-collected data. The present study is based on a dataset of discharges after acute psychiatric admission from hospitals operated by South London and Maudsley NHS Trust and serving the London Boroughs of Croydon, Lambeth, 
Lewisham and Southwark. We have previously published cross-sectional analyses of the associations of homelessness and of residential mobility in this sample [43,44], finding that $16 \%$ of admissions were associated with homelessness, which tended to be present at admission or to be first recorded shortly afterwards, and that $15 \%$ of admissions were associated with residential mobility during the admission or up to 28 days after discharge, with residential mobility tending to be recorded around the time of discharge. Although homelessness and residential mobility were strongly associated, the association was not invariable, with around half of homeless individuals not recorded as moving into new accommodation. We aimed to estimate the associations between LOS and homelessness, residential mobility and other factors, and to estimate the extent to which variation in LOS was accounted for by each of these factors.

\section{Methods}

Data came from the BRC Case Register, which is an anonymised copy of the South London and Maudsley NHS Foundation Trust's paperless electronic patient record database, optimised for data extraction [45] and maintained by the Trust's Biomedical Research Centre (BRC). The Case Register covers all mental health services for much of South London since 2006 and includes structured clinical and administrative data (the main source of data for this analysis) and free-text data. Access to the Case Register is restricted to researchers approved by the BRC, and the BRC's Oversight Committee also granted permission for the present study. Ethical approval is not required as data are fully anonymised.

Details of the sample were previously described $[43,44]$. We initially extracted all psychiatric hospital stays leading to a discharge between 31st December 2007 and 31st December 2009. From these, we selected all hospital stays that had begun on an acute psychiatric ward. (The sample therefore included a small number of individuals who were admitted to acute psychiatric wards, then later transferred to rehabilitation or forensic services, and then discharged.) When the same individual had more than one discharge over this period, the last hospital stay was selected; this avoided clustering effects incompatible with the multiple imputation model used. Length of stay was defined as the difference between the discharge date and admission date in days.

Additional data merged with these were: age, sex, ethnicity, marital status, employment status, recorded ICD10 diagnoses, most restrictive legal status in the seven days after admission, number of psychiatric ward discharges in the two years preceding the index admission date, longest psychiatric admission leading to a discharge in the two years preceding the index admission date, whether any hospital admission leading to discharge in the two years preceding the index admission date had included a period of psychiatric intensive care, admission HoNOS scores, and data describing periods of homelessness or resident in a particular "output area" (these comprise around 500 households). Legal status was classified as informal, Section 2 (which permits detention for up to 28 days), or Section 3 / Forensic (detention for up to six months in the first instance). The nearest multi-axial diagnosis to the date of discharge was selected. A preliminary analysis of the LOS of non-comorbid cases was used to define a diagnostic hierarchy; this was then used to define primary diagnosis if necessary. Variables were also created for lifetime drug and alcohol diagnosis and for residential mobility. Imputing large amounts of data using multinomial logistic regression is computationally intensive and very slow: therefore HoNOS item scores (except problems with living conditions) were recoded as "low" (0-1) or "high" (2-4).

We used Stata version 12 for analysis. Initially, we performed descriptive and unadjusted analyses. After exploring missing data, we then used multiple imputation using chained equations $[46,47]$ to impute the missing values. In addition to the variables listed above, the imputation model included additional predictors of missingness (see Results), and the Nelson-Aalen cumulative hazard estimator for discharge, taken from a Cox regression of LOS fitted without covariates. The number of imputed datasets created (50) was decided on using the rule that this should equal or exceed the percentage of missing values for the variable with the greatest number of these [48], and imputed values were compared with original values.

After transforming LOS to its logarithm, we used linear regression to model the statistical effects of exposure and to estimate both the proportion of variance explained overall $\left(R^{2}\right)$ and incremental effects on $R^{2}$ (the difference in $\mathrm{R}^{2}$ for the final model and a model without the test variable). Although LOS data may be more flexibly modelled using survival analysis, linear regression has the advantage of being consistent with most previous research and of readily yielding estimates of $R^{2}$.

An appropriate functional form for continuous variables (age and longest admission in the preceding two years) was defined using the method of fractional polynomials $[49,50]$, using a dataset with complete data for most important exposure variables (demographics, diagnosis, legal status and housing variables). Subsequent model-building was performed using the imputed datasets, using the Stata mim procedure to combine parameter estimates as per "Rubin's rules" [51]. All exposure variables listed above were included in the full model, with the exception of the HoNOS problems with living conditions item, which was highly correlated with residential mobility and homelessness, and was therefore 
omitted. Following the empirical approach outlined by Hosmer et al. (2008) [52], we first fitted the full model as above, then removed all variables for which the incremental $\mathrm{F}$ test gave $\mathrm{p}>0.25$, and then removed other variables with $\mathrm{p}>0.05$ one-by-one, seeking to retain only those variables whose removal led to substantial change in other coefficients (approximately $20 \%$ or more) and which, when added to the final model, remained insignificant at the $p=0.05$ level. Estimates of average $R^{2}$ were generated as described by Harel (2009) [53]. An estimate of overall $R^{2}$ for the final model was obtained. In order to explore the final model further, estimates of incremental $R^{2}$ were calculated by subtracting the estimated $R^{2}$ for the regression without one or more variable(s) from the overall $\mathrm{R}^{2}$ for the final model.

\section{Results}

There were 4485 admissions. Mode and median LOS were 1 day and 22 days respectively; LOS exhibited a strong right skew $(4.6 ; \mathrm{p}<0.0001)$. This skew was largely abolished by $\log$ transformation $(0.09 ; \mathrm{p}=0.0186)$, and asymmetry was reduced. Sample characteristics are tabulated in Table 1 . Ten subjects were under 18 and 114 (3\%) were over 65 . Values of age were missing for 3 subjects, ethnicity for $92(2 \%)$, address data for $99(2 \%)$, marital status for 355 (8\%) and diagnosis for 393 (9\%). There were more missing data for employment (42\%) and for HoNOS item scores which, for example, were $25 \%$ missing in the case of HoNOS ADL impairment. Missingness for HoNOS items was related to the date of admission, eventual LOS, and the first ward to which the subject was admitted. Other data were complete.

No anomalies were found in the imputed data. Appropriate fractional polynomial transformations were used for age (which was entered as age cubed) and longest admission in the preceding two years (which was entered as its logarithm, together with a dummy variable representing having had no discharge from a psychiatric ward in the two years preceding the index admission date-this was necessary in order to properly fit the regression model to data including a large proportion of zero values [50]).

Seven subjects with outlying values for LOS were omitted from the regression analysis. After fitting of the initial multivariable model, the incremental $F$ test gave $\mathrm{p}>0.25$ for the following variables, which were therefore removed: sex, ethnicity, employment, number of discharges from a psychiatric ward in the two years preceding the index admission date, lifetime diagnosis of a drug and alcohol disorder, the HoNOS overactive, aggressive, disruptive or agitated behaviour item, the HoNOS other mental or behavioural problems item, the HoNOS problems with relationships item and the HoNOS problems with occupation and activities item.
Marital status and the HoNOS problem with drinking or drug-taking item were initially retained, but were removed during the subsequent model building stages ( $\mathrm{p}=0.06$ for addition of marital status to the final model; $p=0.12$ for addition of the HoNOS problems with drinking or drug-taking item).

In the final model, LOS was increased by residential mobility $(\mathrm{p}<0.001)$, homelessness $(\mathrm{p}<0.001)$, diagnosis other than drug and alcohol disorder (in ascending order of magnitude: non-psychotic disorders, other psychotic disorder, then schizophrenia; $\mathrm{p}<0.001$ for each); detained legal status (in ascending order of magnitude: Section 2, then Section 3 or forensic sections; $\mathrm{p}<0.001$ for both); and a high score on the following HoNOS items: cognitive impairment $(\mathrm{p}=0.015)$, physical illness or disability $(\mathrm{p}=0.005)$, hallucinations and delusions $(\mathrm{p}=0.023)$, depressed mood $(\mathrm{p}=0.028)$ and ADL impairment $(\mathrm{p}<0.001)$. LOS was reduced by a high score on the HoNOS self-harm item $(p<0.001)$. As noted above, there were non-linear effects of age $(p<0.001)$ and length of the longest admission in the preceding two years $(\mathrm{p}<0.001)$. Having a short admission in the preceding two years was associated with the shortest LOS; having a long admission with the longest; the effect of no admission was intermediate. LOS was longest for older patients, but the effect of age reduced with decreasing age. In the results table (Table 2), categorybased estimates were generated for these continuous covariates, so that the effects presented are the average effects estimated for bands of values [54]. Results are expressed in their exponentiated form $(\exp \beta)$; therefore they represent multiplicative effects on untransformed values of LOS.

The overall value of $\mathrm{R}^{2}$ for the final model was 0.37 . The incremental $R^{2}$ was greatest for legal status (0.08). For residential mobility, incremental $\mathrm{R}^{2}$ was 0.03 and for homelessness it was 0.01 . In comparison, the value for diagnosis was 0.03 ; for longest previous admission it was 0.01; for the HoNOS activities of daily living item it was 0.01; and both for all the other included HoNOS items together and for age it was less than 0.01 .

\section{Discussion}

We performed a large study of associations with LOS after acute psychiatric admission, aiming to estimate the strength of association between LOS and residential mobility, homelessness and other variables. Both residential mobility and homelessness were strongly associated with increased LOS: the regression analysis indicated that LOS was on average $99 \%$ higher for residential mobility and $45 \%$ higher for homelessness. The only parameter estimates that were greater were for the effect of schizophrenia compared to primary drug and alcohol disorder and for the effect of detention under Section 3 or a 
Table 1 Sample characteristics

\begin{tabular}{|c|c|c|c|c|}
\hline Variable & & $\begin{array}{l}\text { Complete } \\
\text { (\% / total) }\end{array}$ & Measure & \\
\hline Age & & $4482(99.9 \%)$ & Mean (SD) & $39.3(12.3)$ \\
\hline \multirow[t]{2}{*}{ Gender } & Male & $4485(100 \%)$ & N (\%) & $2514(56.1 \%)$ \\
\hline & Female & & & $1971(44.0 \%)$ \\
\hline \multirow[t]{3}{*}{ Ethnicity } & White British & $4393(98.0 \%)$ & N (\%) & $1710(38.9 \%)$ \\
\hline & Black African or Caribbean & & & $1730(39.4 \%)$ \\
\hline & Other & & & $953(21.7 \%)$ \\
\hline \multirow[t]{3}{*}{ Marital status } & Single & $4130(92.1 \%)$ & N (\%) & $2999(72.6 \%)$ \\
\hline & $\begin{array}{l}\text { Divorced / separated / } \\
\text { widowed }\end{array}$ & & & $603(14.6 \%)$ \\
\hline & Married & & & $528(12.8 \%)$ \\
\hline \multirow[t]{2}{*}{ Employed } & No & $2604(58.1 \%)$ & N (\%) & $2316(88.9 \%)$ \\
\hline & Yes & & & $288(11.1 \%)$ \\
\hline \multirow[t]{4}{*}{ Diagnosis } & Drug \& alcohol & $4092(91.2 \%)$ & N (\%) & $370(9.0 \%)$ \\
\hline & Non-psychotic & & & $1175(28.7 \%)$ \\
\hline & Other psychotic ${ }^{a}$ & & & $1285(31.4 \%)$ \\
\hline & Schizophrenia & & & $1262(30.8 \%)$ \\
\hline \multirow[t]{3}{*}{ Legal status $^{\mathrm{b}}$} & Informal & 4485 (100\%) & N (\%) & $2491(55.5 \%)$ \\
\hline & Section $2 \mathrm{MHA}$ & & & $1178(26.3 \%)$ \\
\hline & Section 3 \& Forensic MHA & & & $816(18.2 \%)$ \\
\hline \multirow[t]{5}{*}{ Longest admission in preceding two years } & Nil & $4485(100 \%)$ & N (\%) & $2630(58.6 \%)$ \\
\hline & 1-16 days & & & $477(10.6 \%)$ \\
\hline & 17-39 days & & & $455(10.1 \%)$ \\
\hline & 40-89 days & & & $463(10.3 \%)$ \\
\hline & $90+$ days & & & $460(10.3 \%)$ \\
\hline \multirow[t]{6}{*}{ Number of discharges in preceding two years } & Nil & $4485(100 \%)$ & N (\%) & $2630(58.6 \%)$ \\
\hline & 1 & & & $638(14.2 \%)$ \\
\hline & 2 & & & $522(11.6 \%)$ \\
\hline & 3 & & & $253(5.6 \%)$ \\
\hline & 4 & & & $170(3.8 \%)$ \\
\hline & 5 or more & & & $272(6.1 \%)$ \\
\hline \multirow{2}{*}{$\begin{array}{l}\text { HoNOS \#1 (Overactive, aggressive, } \\
\text { disruptive or agitated behaviour) }\end{array}$} & Nil or minor $(0-1)$ & $3429(76.5 \%)$ & $N(\%)$ & $2015(58.8 \%)$ \\
\hline & Mild to very severe $(2-4)$ & & & $1414(41.2 \%)$ \\
\hline \multirow[t]{2}{*}{ HoNOS \#2 (Non-accidental self-injury) } & Nil or minor (0-1) & $3420(76.3 \%)$ & N (\%) & $2684(78.5 \%)$ \\
\hline & Mild to very severe $(2-4)$ & & & $736(21.5 \%)$ \\
\hline \multirow[t]{2}{*}{ HoNOS \#3 (Problem drinking or drug-taking) } & Nil or minor $(0-1)$ & $3353(74.8 \%)$ & $N(\%)$ & $2351(70.1 \%)$ \\
\hline & Mild to very severe $(2-4)$ & & & $1002(29.9 \%)$ \\
\hline \multirow[t]{2}{*}{ HoNOS \#4 (Cognitive problems) } & Nil or minor (0-1) & $3401(75.8 \%)$ & N (\%) & $2621(77.1 \%)$ \\
\hline & Mild to very severe $(2-4)$ & & & $780(22.9 \%)$ \\
\hline \multirow[t]{2}{*}{ HoNOS \#5 (Physical illness or disability problems) } & Nil or minor (0-1) & $3400(75.8 \%)$ & N (\%) & $2767(81.4 \%)$ \\
\hline & Mild to very severe $(2-4)$ & & & $633(18.6 \%)$ \\
\hline \multirow{2}{*}{$\begin{array}{l}\text { HoNOS \#6 (Problems associated with } \\
\text { hallucinations and delusions) }\end{array}$} & Nil or minor (0-1) & $3397(75.8 \%)$ & N (\%) & $1439(42.4 \%)$ \\
\hline & Mild to very severe (2-4) & & & $1958(57.6 \%)$ \\
\hline \multirow[t]{2}{*}{ HoNOS \#7 (Problems with depressed mood) } & Nil or minor $(0-1)$ & $3407(76.0 \%)$ & $N(\%)$ & $1949(57.2 \%)$ \\
\hline & Mild to very severe $(2-4)$ & & & $1458(42.8 \%)$ \\
\hline
\end{tabular}


Table 1 Sample characteristics (Continued)

HoNOS \#8 (Other mental and behavioural problems)

HoNOS \#9 (Problems with relationships)

HoNOS \#10 (Problems with activities of daily living)

HoNOS \#11 (Problems with living conditions)

HoNOS \#12 (Problems with occupation and activities)
Homeless
Residential mobility during admission or
within 28 days of discharge

Note. Total sample size was 4485

a Other psychotic' comprised ICD-10 codes F21 to F31 inclusive. 'begal status was defined as the most restrictive section of the Mental Health Act in force during

the first week of the admission. Detention only under Section 136, Section 5(2) or Section 5(4) was treated as informal legal status.

\begin{tabular}{llll} 
Nil or minor (0-1) & $3425(76.4 \%)$ & $N(\%)$ & $1475(43.1 \%)$ \\
Mild to very severe (2-4) & & $1950(56.9 \%)$ \\
Nil or minor (0-1) & $3332(74.3 \%)$ & $N(\%)$ & $1814(54.4 \%)$ \\
Mild to very severe (2-4) & & $1518(45.6 \%)$ \\
Nil or minor (0-1) & $3364(75.0 \%)$ & $N(\%)$ & $2179(64.8 \%)$ \\
Mild to very severe (2-4) & & $N(\%)$ & $1185(35.2 \%)$ \\
Nil (0) & $3187(71.0 \%)$ & $1609(50.5 \%)$ \\
Mild (1) & & $621(19.5 \%)$ \\
Moderate (2) & & $434(13.6 \%)$ \\
Moderately severe (3) & & $247(7.8 \%)$ \\
Severe to very severe (4) & & $276(8.7 \%)$ \\
Nil or minor (0-1) & & $1938(60.2 \%)$ \\
Mild to very severe (2-4) & & $1279(39.8 \%)$ \\
Not homeless & & $3667(83.6 \%)$ \\
At admission & & $392(8.9 \%)$ \\
Day 1 onwards & & $327(7.5 \%)$ \\
No & & & $3740(85.2 \%)$ \\
Yes & & $646(14.7 \%)$ \\
\hline
\end{tabular}

forensic section compared to informal legal status. The overall value of $\mathrm{R}^{2}(0.37)$ was higher than many other studies of large samples of admissions, perhaps because we were able to study several variables in addition to those which have usually been studied; the greatest contribution was made by legal status, but the contribution of residential mobility and homelessness together was greater than that of diagnosis. The contribution of other variables was very modest, although the contribution of the HoNOS item scores (and especially that of the HoNOS activities of daily living item) are likely to have been reduced by the need to recode them as dichotomous variables. The contributions of homelessness and residential mobility are particularly notable given that these exposures were present in only $16 \%$ and $15 \%$ of cases respectively.

\section{Comparison with previous studies}

Most large US studies have found effects of diagnosis and age; some have also described interactions between age and diagnosis, which we did not test for [55,56], and non-linear effects of age $[57,58]$. US studies have typically found a small increase in LOS for female patients which we did not observe [57-63]. The large effects of legal status are opposite to those in the US, where civil commitment procedures are typically of shorter duration, and a spike in discharge may be demonstrated at the end of the committed period [62], but they are similar to those observed in UK data collected in the 1980s and early 1990s [5].

Effects of previous service use have been inconsistent in the US literature [4]. We demonstrated a highly significant relationship between LOS and the length of the longest admission in the preceding two years. In contrast, there was no effect of the absolute number of previous discharges, although modelling the effect of previous LOS did require the additional inclusion of a dummy variable for having had no hospital admission in the relevant period. The novel finding that patients who had not had a previous admission had LOS intermediate between those with a short previous stay and a long previous stay is presumably explained by an underlying dimension of illness severity which influences a person's past, current and future LOS. In the group with no previous admission, there is no outward expression of this underlying dimension; furthermore, individuals within this group would also be expected to exhibit the entire range of severity, with the overall effect observed therefore representing an averaging process.

We found no effect of drug and alcohol use comorbid with primary mental disorder (as measured by HoNOS and lifetime ICD-10 diagnosis), although a primary diagnosis of drug and alcohol use was strongly associated with shorter LOS. Findings in relation to this effect of "dual-diagnosis" in smaller US studies of unselected psychiatric patients have been conflicting [4], but a similar 
Table 2 Linear regression model

\begin{tabular}{|c|c|c|c|c|}
\hline Variable & & $\exp \beta(95 \% \mathrm{Cl})$ & incremental $\mathrm{R}^{2}$ & $\mathbf{P}$ \\
\hline Residential mobility & & $1.99(1.80,2.20)$ & 0.028 & $<0.001$ \\
\hline Homelessness & & $1.45(1.32,1.60)$ & 0.009 & $<0.001$ \\
\hline \multirow[t]{4}{*}{ Legal status $^{1}$} & & & 0.082 & $<0.001$ \\
\hline & Informal & 1 & & \\
\hline & Section 2 & $1.86(1.71,2.02)$ & & \\
\hline & Section 3 or Forensic & $3.06(2.78,3.38)$ & & \\
\hline \multirow[t]{6}{*}{ Age / years ${ }^{2}$} & & & 0.003 & $<0.001$ \\
\hline & $16-25$ & 1 & & \\
\hline & $26-35$ & $1.00(1.00,1.00)$ & & \\
\hline & $36-45$ & $1.02(1.01,1.03)$ & & \\
\hline & $46-55$ & $1.08(1.04,1.12)$ & & \\
\hline & $56-65$ & $1.20(1.10,1.30)$ & & \\
\hline \multirow[t]{5}{*}{ Diagnosis } & & & 0.029 & $<0.001$ \\
\hline & Drug and alcohol & 1 & & \\
\hline & Non-psychotic & $1.35(1.18,1.53)$ & & \\
\hline & Other psychotic & $1.88(1.65,2.15)$ & & \\
\hline & Schizophrenia & $2.33(2.03,2.67)$ & & \\
\hline \multirow[t]{5}{*}{ Longest admission in preceding 2 years ${ }^{3}$} & None & 1 & 0.011 & $<0.001$ \\
\hline & $1-16$ days & $0.98(0.89,1.07)$ & & \\
\hline & 17-39 days & $1.18(1.10,1.26)$ & & \\
\hline & 40-71 days & $1.31(1.22,1.41)$ & & \\
\hline & $90+$ days & $1.53(1.39,1.68)$ & & \\
\hline HoNOS \#2 & Mild to very severe & $0.79(0.72,0.87)$ & 0.004 & $<0.001$ \\
\hline HoNOS \#4 & Mild to very severe & $1.14(1.03,1.27)$ & 0.002 & 0.015 \\
\hline HoNOS \#5 & Mild to very severe & $1.16(1.05,1.29)$ & 0.002 & 0.005 \\
\hline HoNOS \#6 & Mild to very severe & $1.10(1.01,1.20)$ & 0.001 & 0.023 \\
\hline HoNOS \#7 & Mild to very severe & $1.11(1.01,1.21)$ & 0.001 & 0.028 \\
\hline HoNOS \#10 & Mild to very severe & $1.38(1.27,1.49)$ & 0.011 & $<0.001$ \\
\hline
\end{tabular}

Note. $\mathrm{N}=4478$ after subtraction of seven observations with outlying values for LOS. Overall $r 2$ was $0.368 .{ }^{1}$ Legal status was defined as the most restrictive section of the Mental Health Act in force during the first week of the admission. Those detained only under Section 136, Section 5(2) or Section 5(4) were treated as informal. ${ }^{2}$ Exponentiated coefficients for age-band are category-based estimates derived from the full regression model. Reference points for age used to generate these estimates were $20,30,40,50$ and 60 years. ${ }^{3}$ Reference points for the category-based estimates for the effect of length of the longest previous admission were the median values of log previous LOS in each band.

lack of consistent effect was reported in a study of over 20,000 schizophrenia and affective psychosis discharges in Arizona, California and Maryland [64]. In relation to the HoNOS items, the unadjusted effect of the problems with living conditions item and the adjusted effect of the self-harm, depressed mood and ADL impairment and items are consistent with the Australian study cited above [14], but we did not replicate the associations found with the aggressive behaviour item. Differences between this and our study may reflect differences in the construction of the regressions, different coding of the diagnosis item, the inclusion of legal status in our analysis, and greater statistical power of our analysis. We suggest that these effects may readily be interpreted in terms of their effect on the quantity of care required; this includes the effect seen of suicidality, where the reduced LOS presumably reflects the typically rapid resolution of such symptoms relative to other symptoms, with consequent discharge.

\section{Limitations}

Our data derive only from a single English NHS Trust serving predominantly inner city neighbourhoods. Comparison of unadjusted figures from our study with 2008-2009 Hospital Episode Statistics for England demonstrates possibly greater LOS in our service. For example, median length of stay in England for adult mental health services in this period was 17 days; for 
detained patients with schizophreniform psychosis it was 57 days [65]. As the effects of homelessness and residential mobility are presumably due to their effect on clinical decision-making, the extent to which these findings would generalise to other countries is uncertain; however, it is clear that homelessness and residential mobility themselves are common among psychiatric inpatients in most developed countries (see Introduction).

\section{Conclusions}

Residential mobility and, to a lesser extent, homelessness appeared to have very significant effects on LOS within our sample. The effects are clearly detectable within the whole sample, but apply especially to the minority of individuals who are directly affected.

The starting point of any discussion of residential mobility should be to note that, considered in the round, voluntary residential mobility is the most important way in which people are able to adjust their housing to their needs [66], and the same is likely to apply to people to with and without a mental illness. However, evidence from studies of residential mobility among individuals with mental illness tends to suggest that forced, rather than voluntary, mobility may predominate, especially among individuals admitted to hospital: we have previously reported that wish to move and dissatisfaction with housing were unassociated with residential mobility in a population of individuals with severe mental illness [42]; furthermore, homelessness - which is unlikely to be voluntary-was strongly associated with residential mobility in the present sample [44], and the phenomenon of eviction at or around the time of hospital admission has previously been described [30,67]. Certainly, one future avenue for research would be to clarify the circumstances of inpatient residential moves and whether any proportion of them would have been better averted, investigations that would perhaps lead into better interventions to support tenancy sustainment.

Realistically, however, residential mobility is likely to remain a feature of a minority of psychiatric hospital admissions, and attention should also be focused on attempts to increase the supply of suitable housing units and to speed up the processes by which these are made available. Not only would this significantly reduce hospital bed-use (on the evidence of the present study) it would also mean that the individuals affected do not themselves have to suffer protracted and essentially unproductive admissions. Furthermore, the importance of residential mobility has significant implications for the design of psychiatric payment systems. Most obviously, systems that do not reimburse providers for the excess LOS of those awaiting new housing will impose very significant costs on providers, with the likely consequence that more patients will be discharged to unsuitable accommodation or discharged homeless. An alternative would be to attempt to reimburse costs imposed on providers - for example by paying a premium on top of the normal per case payment, or through making a per diem payment; but while this may avoid random risk to providers, it is a sub-optimal (allocatively inefficient) solution, as it would lead to greater resources being expended on healthcare, where this would yield little benefit, than on housing, where it would. The most efficient solutions are likely to be those that lead to a proper allocation of resources between healthcare and housing. In the UK, a system of cross-charging has been introduced whereby hospitals may impose fines on local authorities who do not provide appropriate community resources for elderly medical patients, and, although the effectiveness of this solution has been questioned [68], its extension to mental health services has been considered [18]. An alternative would be to pool housing and health resources, perhaps with health providers taking on the responsibility to provide housing for some of their users.

\section{Competing interests}

The authors have no competing interests.

\section{Authors' contributions}

AT devised the study in association with PF and AD. AT constructed the data set, performed multiple imputation analysis (with assistance from MK), performed analysis (with support from MK) and wrote drafts of the manuscript. All authors reviewed and corrected the manuscript, and approved the final version.

\section{Acknowledgement}

AT was funded by the UK Medical Research Council when the research started; AT and MK are currently supported by the NIHR Biomedical Research Centre for Mental Health at the South London and Maudsley NHS Foundation Trust and Institute of Psychiatry, Kings College London. The study used NIHR Biomedical Research Centre infrastructure funded by NIHR and the Guy's and St. Thomas' Hospital Trustees. We gratefully acknowledge the help of Dr Rob Stewart and Mr Matthew Broadbent.

\section{Author details}

'King's College London, King's Health Partners, Institute of Psychiatry, De Crespigny Park, London SE5 8AF, UK. ${ }^{2}$ NIHR Specialist Biomedical Centre for Mental Health, Maudsley Hospital, London SE5 8AZ, UK. ${ }^{3}$ Trinity College Dublin and St Patrick's University Hospital Dublin, James's Street, Dublin 8, Eire.

Received: 21 December 2011 Accepted: 2 August 2012

Published: 21 August 2012

\section{References}

1. Blader JC: Acute Inpatient Care for Psychiatric Disorders in the United States, 1996 Through 2007. Arch Gen Psychiatry 2011, 68:1276-1283.

2. Thompson A, Shaw M, Harrison G, Ho D, Gunnell D, Verne J: Patterns of hospital admission for adult psychiatric illness in England: analysis of Hospital Episode Statistics data. Br J Psychiatry 2004, 185:334-341.

3. Audit Commission: Maximising resources in adult mental health. London: Audit Commission; 2010.

4. Tulloch AD, Fearon P, David AS: Length of stay of general psychiatric inpatients in the United States: systematic review. Adm Policy Ment Health 2011, 38:155-68.

5. Hodgson R, Lewis M, Boardman J: The prediction of in-patient length of stay for acute psychiatric admissions. J Ment Health 2000, 9:145-153.

6. McCrone P, Phelan M: Diagnosis and length of psychiatric in-patient stay. Psychol Med 1994, 24:1025-1030. 
7. Stevens A, Hammer K, Buchkremer G: A statistical model for length of psychiatric in-patient treatment and an analysis of contributing factors. Acta Psychiatr Scand 2001, 103:203-211.

8. Oiesvold T, Saarento O, Sytema S, Christiansen L, Göstas G, Lönnerberg O, Muus S, Sandlund M, Hansson L: The Nordic Comparative Study on Sectorized Psychiatry-length of in-patient stay. Acta Psychiatr Scand 1999, 100:220-228.

9. Brown TM, Miller HL, Ekstrom D, Evans DL, Golden RN: Characteristics of long-stay patients on the psychiatric service of a university hospital. Hosp Community Psychiatry 1991, 42:743-745.

10. Jakubaschk J, Kopp W: On characterizing new psychiatric long-stay patients. Soc Psychiatry Psychiatr Epidemiol 1989, 24:88-95.

11. Jakubaschk J, Waldvogel D, Würmle O: Differences between long-stay and short-stay inpatients and estimation of length of stay. A prospective study. Soc Psychiatry Psychiatr Epidemiol 1993, 28:84-90.

12. Warnke I, Rössler W: Length of stay by ICD-based diagnostic groups as basis for the remuneration of psychiatric inpatient care in Switzerland? Swiss Med Wkly 2008, 138:520-527.

13. Wing JK, Beevor A, Curtis R, Park S, Hadden S, Burns A: Health of the Nation Outcome Scales (HoNOS). Research and development. $\mathrm{Br} J$ Psychiatry 1998, 172:11-18.

14. Boot B, Hall W, Andrews G: Disability, outcome and case-mix in acute psychiatric in-patient units. Br J Psychiatry 1997, 171:242-246.

15. Salit SA, Kuhn EM, Hartz AJ, Vu JM, Mosso AL: Hospitalization costs associated with homelessness in New York City. N Engl J Med 1998, 338:1734-40.

16. McGuire J, Mares A: Hoptel equalizes length of stay for homeless and domiciled inpatients. Med Care 2000, 38:1003-10.

17. Tulloch AD, Fearon P, David AS: The determinants and outcomes of longstay psychiatric admissions - a case-control study. Soc Psychiatry Psychiatr Epidemiol 2008, 43:569-574.

18. Glasby J, Lester $\mathrm{H}$ : Delayed hospital discharge and mental health: the policy implications of recent research. Soc Policy Admin 2004, 38:744-757.

19. House of Commons Health Committee: Delayed discharges. Third report of session 2001-2002, volume 1. London: Stationery Office; 2002.

20. Mann SA, Cree W: New long-stay psychiatric patients: National sample survey of 15 mental hospitals in England and Wales 1972-3. Psychol Med 1976, 6:603-616.

21. Lelliott $P$, Wing JK A national audit of new long-stay psychiatric patients. II: Impact on services. Br J Psychiatry 1994, 165:170-178.

22. Holloway $F$, Wykes $T$, Petch $E$, Lewis-Cole K: The new long stay in an inner city service: a tale of two cohorts. Int J Soc Psychiatry 1999, 45:93-103.

23. Fulop N, Koffman J, Hudson M: Challenging bed behaviours: the use of acute psychiatric beds in an inner London District Health Authority. J Ment Health 1992, 1:335-341.

24. Fulop N, Koffman J, Carson S, Robinson A, Pashley D, Coleman K: Use of acute psychiatric beds: a point prevalence survey in North and South Thames regions. J Public Health 1996, 18:207-216.

25. Shepherd G, Beadsmoore A, Moore C, Hardy P, Muijen M: Relation between bed use, social deprivation, and overall bed availability in acute adult psychiatric units, and alternative residential options: a cross sectional survey, one day census data, and staff interviews. Br Med J 1997, 314:262.

26. Appleby L, Desai PN: Documenting the relationship between homelessness and psychiatric hospitalization. Hosp Community Psychiatry 1985, 36:732-737.

27. Ash D, Haynes J, Braben P, Galletly C: Violence, self-harm, victimisation and homelessness in patients admitted to an acute inpatient unit in South Australia. Int J Soc Psychiatry 2003, 49:112-118.

28. Fisher N, Turner S, Pugh R: Homeless and mentally ill. Lancet 1990, 335:916-917.

29. Herman DB, Susser ES, Jandorf L, Lavelle J, Bromet EJ: Homelessness among individuals with psychotic disorders hospitalized for the first time: findings from the Suffolk County Mental Health Project. Am J Psychiatry 1998, 155:109-113.

30. Herzberg JL: No fixed abode. A comparison of men and women admitted to an East London psychiatric hospital. Br J Psychiatry 1987, 150:621-627.

31. Koffman J, Fulop N: Homelessness and the use of acute psychiatric beds: findings from a one-day survey of adult acute and low-level secure psychiatric patients in North and South Thames regions. Health and Social Care in the Community 1999, 7:140-147.
32. Mowbray $C T$, Johnson VS, Solarz A: Homelessness in a state hospital population. Hosp Community Psychiatry 1987, 38:880-882.

33. Rosenheck R, Seibyl C: Homelessness: health service use and related costs. Med Care 1998, 36:1256-1264.

34. Susser ES, Lin SP, Conover SA: Risk factors for homelessness among patients admitted to a state mental hospital. Am J Psychiatry 1991, 148:1659-1664.

35. Whiteley JS: Down and out in London; mental illness in the lower social groups. Lancet 1955, 269:609-610.

36. Appleby L, Desai PN: Residential instability: a perspective on system imbalance. Am J Orthopsychiatry 1987, 57:515-524.

37. Caton $\mathrm{CL}$, Goldstein J: Housing change of chronic schizophrenic patients: a consequence of the revolving door. Soc Sci Med 1984, 19:759-64.

38. DeVerteuil G, Hinds A, Lix LM, Walker J, Robinson R, Roos LL: Mental health and the city: intra-urban mobility among individuals with schizophrenia. Health Place 2007, 13:310-323.

39. Lix LM, DeVerteuil G, Walker JR, Robinson JR, Hinds AM, Roos LL: Residential mobility of individuals with diagnosed schizophrenia - a comparison of single and multiple movers. Soc Psychiatry Psychiatr Epidemiol 2007, 42:221-228.

40. Lix LM, Hinds A, DeVerteuil G, Robinson JR, Walker J, Roos LL: Residential mobility and severe mental illness: a population-based analysis. Adm 2006, 33:160-171.

41. McCarthy JF, Valenstein M, Blow FC: Residential mobility among patients in the VA health system: associations with psychiatric morbidity, geographic accessibility, and continuity of care. Adm Policy Ment Health 2007, 34:448-455.

42. Tulloch AD, Fearon P, Fahy T, David AS: Residential mobility among individuals with severe mental illness: cohort study of UK700 participants. Soc Psychiatry Psychiatr Epidemiol 2010, 45:767-777.

43. Tulloch AD, Fearon P, David AS: Timing, prevalence and associations of homelessness among acute psychiatric inpatients. Soc Psychiatry Psychiatr Epidemiol 2012, 47:1181-1191.

44. Tulloch AD, Fearon P, David AS: Residential mobility among patients admitted to acute psychiatric wards. Health Place 2011, 17:859-866.

45. Stewart R, Soremekun M, Perera G, Broadbent M, Callard F, Denis M, Hotopf M, Thornicroft G, Lovestone S: The South London and Maudsley NHS Foundation Trust Biomedical Research Centre (SLAM BRC) case register: development and descriptive data. BMC Psychiatry 2009, 9:51.

46. van Buuren S, Boshuizen HC, Knook DL: Multiple imputation of missing blood pressure covariates in survival analysis. Stat Med 1999, 18:681-694

47. Royston P: Multiple imputation of missing values. Stata J 2004, 4:227-241.

48. White IR, Royston P, Wood AM: Multiple imputation using chained equations: Issues and guidance for practice. Statistics in Medicine 2011, 30:377-399.

49. Royston $P$, Ambler $G$, Sauerbrei W: The use of fractional polynomials to model continuous risk variables in epidemiology. Int J Epidemiol 1999, 28:964-974.

50. Royston P, Sauerbrei W, Becher H: Modelling continuous exposures with a "spike" at zero: A new procedure based on fractional polynomials. Stat Med 2010, 29:1219-1227.

51. Rubin DB: Multiple imputation for nonresponse in surveys. New York: John Wiley \& Sons, Inc:; 1987.

52. Hosmer DW, Lemeshow S, May S: Applied survival analysis: regression modeling of time-to-event data. Hoboken, New Jersey: John Wiley \& Sons, Inc.; 2008 .

53. Harel O: The estimation of R2 and adjusted $\mathrm{R} 2$ in incomplete data sets using multiple imputation. Journal of Applied Statistics 2009, 36:1109-1118.

54. Royston P, Sauerbrei W: Multivariable model-building: a pragmatic approach to regression analysis based on fractional polynomials for modelling continuous variables. Chichester: John Wiley \& Sons, Ltd; 2008.

55. Taube CA, Lee ES, Forthofer RN: DRGs in psychiatry: an empirical evaluation. Med Care 1984, 22:597-610.

56. Ashcraft ML, Fries BE, Nerenz DR, Falcon SP, Srivastava SV, Lee CZ, Berki SE, Errera P: A psychiatric patient classification system. An alternative to diagnosis-related groups. Med Care 1989, 27:543-557.

57. Lave JR, Frank RG: Hospital supply response to prospective payment as measured by length of stay. Adv Health Econ Health Serv Res 1990, $11: 1-25$.

58. Rupp A, Steinwachs DM, Salkever DS: Hospital payment effects on acute inpatient care for mental disorders. Arch Gen Psychiatry 1985, 42:552-5. 
59. Frank RG, Lave JR: The effect of benefit design on the length of stay of Medicaid psychiatric patients. Journal of Human Resources 1986, 21:321-37.

60. Freiman MP, Ellis RP, McGuire TG: Provider response to Medicare's PPS: reductions in length of stay for psychiatric patients treated in scatter beds. Inquiry 1989, 26:192-201.

61. Lave JR, Frank RG: Effect of the structure of hospital payment on length of stay. Health Serv Res 1990, 25:327-47.

62. Stern S, Merwin E, Holt F: Survival models of community tenure and length of hospital stay for the seriously mentally ill: a 10-year perspective. Health Serv Outcomes Res Methodol 2001, 2:117-135.

63. Wallen J: Resource use by psychiatric patients in community hospitals: the influence of illness severity, physician specialty, and presence of a psychiatric unit. Adv Health Econ Health Serv Res 1987, 8:103-26.

64. Bradley CJ, Zarkin GA: Inpatient stays for patients diagnosed with severe psychiatric disorders and substance abuse. Health Serv Res 1996, 31:387-408.

65. Hospital Episode Statistics for England: Inpatient statistics; 2008-2009. http:// www.hesonline.nhs.uk/Ease/servlet/AttachmentRetriever?site_id=1937\& file_name=d:lefmfiles $\backslash 1937 \backslash$ Accessing $\backslash$ DataTables $\backslash H R G \backslash H R G \_0809$. xls\&short_name=HRG_0809.xls\&u_id=8577.

66. Rossi PH: Why families move: a study in the social psychology of urban residential mobility. Glencoe, llinois: Free Press; 1955.

67. Lamont A, Ukoumunne OC, Tyrer P, Thornicroft G, Patel R, Slaughter J: The geographical mobility of severely mentally ill residents in London. Soc Psychiatry Psychiatr Epidemiol 2000, 35:164-169.

68. McCoy D, Godden S, Pollock AM, Bianchessi C: Carrot and sticks? The Community Care Act (2003) and the effect of financial incentives on delays in discharge from hospitals in England. J Public Health 2007, 29:281-287.

doi:10.1186/1471-244X-12-121

Cite this article as: Tulloch et al: Associations of homelessness and residential mobility with length of stay after acute psychiatric admission. BMC Psychiatry 2012 12:121.

\section{Submit your next manuscript to BioMed Central and take full advantage of:}

- Convenient online submission

- Thorough peer review

- No space constraints or color figure charges

- Immediate publication on acceptance

- Inclusion in PubMed, CAS, Scopus and Google Scholar

- Research which is freely available for redistribution 